\title{
Research on Internal Solitary Wave Detection and Analysis Based on Interferometric Imaging Radar Altimeter Onboard the Tiangong-2 Space Laboratory
}

\author{
Hao Zhang ${ }^{1,2,3} \mathbb{D}$, Chenqing Fan ${ }^{2,3}$, Junmin Meng ${ }^{2,3, *}$, Shibao Li ${ }^{1}$ and Lina Sun ${ }^{2,3}$ \\ 1 College of Oceanography and Space Informatics, China University of Petroleum, Qingdao 266061, China; \\ zhanghao@fio.org.cn (H.Z.); Lishibao@upc.edu.cn (S.L.) \\ 2 First Institute of Oceanography, Ministry of Natural Resources, Qingdao 266061, China; \\ fanchenqing@fio.org.cn (C.F.); sunln@fio.org.cn (L.S.) \\ 3 Technology Innovation Center for Ocean Telemetry, Ministry of Natural Resources, Qingdao 266061, China \\ * Correspondence: mengjm@fio.org.cn
}

check for updates

Citation: Zhang, H.; Fan, C.; Meng, J.; Li, S.; Sun, L. Research on Internal Solitary Wave Detection and Analysis Based on Interferometric Imaging Radar Altimeter Onboard the Tiangong-2 Space Laboratory. Remote Sens. 2022, 14, 174. https:// doi.org/10.3390/rs14010174 Academic Editors: Xiao Hua Wang and Yue Ma

Received: 18 November 2021 Accepted: 30 December 2021 Published: 31 December 2021

Publisher's Note: MDPI stays neutral with regard to jurisdictional claims in published maps and institutional affiliations.

Copyright: (C) 2021 by the authors. Licensee MDPI, Basel, Switzerland. This article is an open access article distributed under the terms and conditions of the Creative Commons Attribution (CC BY) license (https:// creativecommons.org/licenses/by/ $4.0 /)$.

\begin{abstract}
The Tiangong-2 space laboratory was launched by China on 15 September 2016, carrying the Interferometric Imaging Radar Altimeter (InIRA), the first of the latest generation of imaging altimeters that can perform imaging and acquire elevation information simultaneously. This paper analyzes the feasibility of using InIRA images to obtain two-dimensional characteristics of oceanic internal solitary waves (ISWs) and information about vertical sea surface fluctuations caused by the propagation of ISWs. The results show that InIRA demonstrates a relatively reliable ability to observe ISWs with high resolution and can identify the fine-scale features of ISWs of different forms. Furthermore, InIRA can observe centimeter-level changes in the Sea Surface Height Anomaly (SSHA) caused by ISWs. The geometric relationship between the sensor's flight direction and the propagation direction of ISWs does not affect its detection effect. However, the swath width of InIRA is too narrow to fully capture ISW information, and the height accuracy of InIRA height product images is not insufficient to detect the height information of small-scale ISWs. These shortcomings need to be considered in the future development of imaging altimeters to increase their potential for detecting mesoscale phenomena in the ocean.
\end{abstract}

Keywords: internal solitary waves; Tiangong-2; interferometric imaging radar altimeter; sea surface height anomaly

\section{Introduction}

The generation and propagation of oceanic internal solitary waves (ISWs) play important roles in the development and utilization of marine resources, fishery stocking and fishing, and marine navigation. ISWs, which refer to the fluctuations generated in the stable density-stratified ocean, exhibit the largest amplitude in the interior of the ocean [1]. The length of the wave crest can laterally stretch hundreds of kilometers, the period generally ranges from a few minutes to tens of hours, and the maximum measured amplitude on record is $240 \mathrm{~m}$ [2].

At present, the methods commonly used for observing ISWs include field measurements, optical remote sensing observations, and synthetic aperture radar (SAR) remote sensing observations. These three methods have unique advantages and disadvantages in the study of ISWs. For example, on-site observation surveys can obtain accurate temperature and salinity profiles and amplitude information but are expensive and cannot be conducted at a large scale $[3,4]$, whereas optical remote sensing platforms can be utilized to investigate the characteristics of ISWs over broad areas but are greatly restricted by clouds, fog and solar flares [5-7]. In contrast, SAR sensors can observe ISWs at all times of day and under all weather conditions without being affected by the environment; thus, SAR 
has been widely used to calculate the statistics of ISWs, invert their parameters and other research [8-14].

When ISWs propagate in the ocean, they not only modulate the redistribution of microscale waves on the sea surface, thereby producing convergence and divergence phenomena [15], but also induce vertical fluctuations of the sea surface [16]. However, SAR and optical remote sensing platforms mainly observe the two-dimensional information after the ISWs trigger the former phenomenon and cannot obtain the Sea Surface Height Anomaly (SSHA). Nevertheless, the SSHA caused by ISWs can be detected with the introduction of another kind of sensor, that is, an active microwave sensor-radar altimeter that measures changes in the surface height [17]. The purpose of radar altimetry over the ocean is to determine the shape of the sea surface by remote sensing detection. An altimeter determines the distance to the ocean surface according to the round-trip travel time of the satellite signal between the sea surface and the sensor and extracts the required parameter information according to the waveform of the signal returned by the sea surface and received by the altimeter [18]. Satellite altimetry technology has experienced rapid development, and with it, the accuracy of radar altimeters has constantly improved; SSHA measurements can already be performed with centimeter-level accuracy, making it possible to study the characteristics of sea surface fluctuations caused by the propagation of ISWs. At present, three generations of radar altimeters have been developed. The first generation is the traditional radar altimeter represented by the TOPEX and Jason series [19]; the second generation is the Synthetic Aperture Radar Altimeter (SARL) carried by the Sentinel-3 satellites [20,21]; and the third generation comprises imaging radar altimeters, such as the Interferometric Imaging Radar Altimeter (InIRA) carried by Tiangong-2 [22-24] and the Ka-band Radar Interferometer (KaRIn) carried by the Surface Water and Ocean Topography (SWOT) mission $[25,26]$.

To date, some scholars have used altimeters to study oceanic ISWs. For example, using traditional radar altimetry, Magalhaes et al., 2017 applied Jason-2 $20 \mathrm{~Hz}$ observation data and quasi-synchronous SAR images to study ISW-modulated altimeter signals and demonstrated that traditional $20 \mathrm{~Hz}$ altimeter observation data can be used to study ISWs [16]. Zhang et al., 2018 used Jason-2 observation data to study ISWs in the South China Sea (SCS) and found that the Ku band ocean surface normalized radar cross-section $(\sigma 0)$ for Jason-2 is more effective at detecting the modulation due to ISWs than the C-band significant wave height (SWH) [27]. Santos-Ferreira et al., 2018 used images acquired by SARL and the Ocean and Land Colour Instrument (OLCI) onboard Sentinel-3 to verify that short-period ISWs can be detected by altimeter signals such as the radar backscatter coefficient, sea level anomaly (SLA) and SWH [28]. Zhang et al., 2020 obtained synchronous images of ISWs near Dongsha Island in SCS based on Sentinel-3 satellite observations and found that SARL can observe the sea surface undulations caused by the propagation of oceanic ISWs; their remote sensing investigation confirmed that the highest point of the ISW-induced sea surface undulation is consistent with the position of the maximum vertical displacement of oceanic ISWs [29]. In 2020, Santos-Ferreira et al. showed that standard level2 (L2) SARL data from Sentinel-3B can predict the amplitude and velocity of ISWs [30]. In addition, da Silva et al. analyzed the ability of SARL to detect ISWs and measure their amplitude in deep waters and proposed, for the first time, that SLAs related to ISWs are dependent on the variation in the differential mean square slope of the wave characteristics [31].

Compared with the first two generations of radar altimeters, imaging radar altimeters combine the existing height measurement technology with SAR technology and interferometric technology. New-generation altimeters have the advantages of a high resolution, a wide swath, the ability to acquire high-quality imagery, and compatibility with both land and sea environments [32]. Imaging altimeters currently under development mainly include InIRA carried by China's Tiangong- 2 space laboratory (Tiangong-2) and KaRIn carried by the SWOT satellite jointly developed by the United States and France. As a satellite equipped with a dedicated three-dimensional imaging altimeter, SWOT, which is 
expected to be launched in 2022 is expected to provide a large amount of data support for oceanographic research. However, a large amount of valid data has already been acquired by China's Tiangong-2, which was launched on 15 September 2016, and is equipped with a prototype of InIRA. For example, Yang et al., 2017 conducted a preliminary quantitative analysis and inversion on the first batch of InIRA data from Tiangong-2 and obtained information on the sea surface wind speed, wavelength, wave direction and SWH [33]. Kong et al., 2017 analyzed the accuracy of sea level measurements using InIRA data from Tiangong-2 in part of the South China Sea [34]. Bao et al., 2018 [35] and Ren et al., 2021 [36] each established sea surface wind speed inversion algorithms for InIRA under small incident angles. Liu et al., 2019 developed a land classification algorithm based on a deep neural learning network using InIRA data and multispectral data [37]. Liu et al., 2019 [38] and Wang et al., 2019 [39] carried out research on the extraction of water body information and the detection of ocean vortices-based on InIRA data. Ren et al., 2021 applied InIRA data to retrieve SWH and used the retrieved data to correct the sea state deviation of the $\mathrm{SSH}$ measured by InIRA [40]. Figure 1 shows a schematic diagram of the Tiangong-2 InIRA instrument.

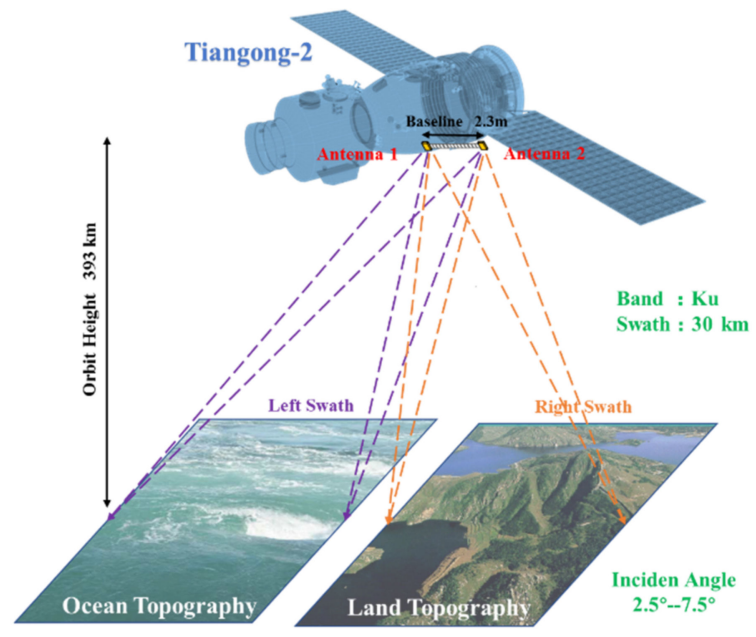

Figure 1. Schematic diagram of the Tiangong-2 InIRA instrument.

The above review demonstrates that methods employing traditional altimeters to detect ISWs are relatively mature and that research is rapidly being performed on ocean dynamic phenomena and target detection based on imaging radar altimeters. However, little has been done to assess the capability of imaging radar altimeters in the study of ISWs. The InIRA instrument carried by China's Tiangong-2 can already provide users with level-2 (L2) and level-4 (L4) data: the L2 data include mainly the $\sigma 0$ signal after geocoding, whereas the $\mathrm{L} 4$ data comprise the elevation data obtained after interferogram processing. This paper mainly uses the L2 and L4 data obtained by InIRA to carry out a study on the feasibility of using imaging altimeters to detect ISWs and analyzes the influence of the imaging altimeter system design on the detection of ISWs.

The remainder of this article is structured as follows: Section 1 presents the introduction; Section 2 introduces the data; Section 3 specifically analyzes the advantages of using the InIRA instrument carried by Tiangong- 2 to obtain the two-dimensional and vertical information of ISWs; Section 4 discusses some problems of InIRA; and Section 5 summarizes the findings.

\section{Data}

\subsection{InIRA Format}

InIRA is the world's first ocean microwave sensor that uses short-baseline, small-angle interferometric technology for wide-sweep sea surface observations; in addition, it can 
acquire observations over land. InIRA operates in the $\mathrm{Ku}$ band $(13.58 \mathrm{GHz})$, the baseline distance is $2.3 \mathrm{~m}$, and the incident angle range is $2.5-7.5^{\circ}$. There are two working modes, namely, conventional observation and high-resolution observation, with swath widths of 30 and $5 \mathrm{~km}$, respectively.

InIRA can currently distribute three levels of data to users: L1, L2 and L4. The L1 products comprise a multitude of multi-look complex images that have undergone imaging processing, azimuth multi-look processing, and radiation correction. The L2 products are geometrically corrected on the basis of the L1 products to form two-dimensional images with a map projection. The distributed files include XML metadata and GeoTIFF data (normalized radar cross section, NRCS). The L4 products form a regular grid of digital elevation model (DEM) products based on the previous levels of data; these products offer image data containing elevation information, and the distributed files include XML metadata and GeoTIFF data (DEM).

For conventional observation modes, InIRA can provide L1, L2, and L4 product data, and the spatial resolution is $40 \mathrm{~m}$. In addition, the relative measurement accuracy of L4 product data on the ocean surface is $20 \mathrm{~cm}$. However, the high-resolution observation mode provides only L1 and L2 products with a spatial resolution of $30 \mathrm{~m}$.

The naming rules for InIRA data products contain the following identifiers (in order): platform identification, load identification, product type identification, data type identification, data sampling start time, data sampling end time, product level, orbit data number, image data number, product processing time, and processing software version number, (for example, T2-IALT-RIM1-SCI-20180206045642-20180206050213-L2-1-18-20180419131630V200.tif, where RIM1 represents normal-mode channel 1 data).

\subsection{Data Used}

The mechanism by which SAR images ISWs consists of the modulation of sea surface microscale waves through the radiative convergence and divergence effect, which changes the roughness of the sea surface, thereby altering the backscatter coefficient received by the SAR sensor, and thus ISWs appear as bright and dark bands in SAR images [15]. Therefore, ISWs should similarly appear as light and dark bands in InIRA images. After submitting an application to the China Manned Space Engineering Office, a total of 230 scenes of L2 images of the main and auxiliary channels and some scenes of L4 images containing the characteristics of ISWs were downloaded. The downloaded images are mainly distributed in sea areas where ISWs frequently occur, such as the SCS, the Sea of Japan, the Andaman Sea and the Celebes Sea.

Figure 2 shows the two sets of L2 images used in this article. The first set of images was acquired in SCS on 23 September 2016 and contains data from the main and auxiliary channels; the second set of images was obtained in the Celebes Sea on 1 June 2018 and includes data obtained by two antennas. The characteristics of ISWs can be clearly identified from Figure 2. The ISWs shown in Figure $2 a, b$ exist in the form of two single solitons, while those in Figure 2c,d exist as wave packets containing at least five solitons each. In addition, the two antennas of InIRA have short baselines; thus, the sea surface radar backscatter coefficient maps obtained are almost identical. 

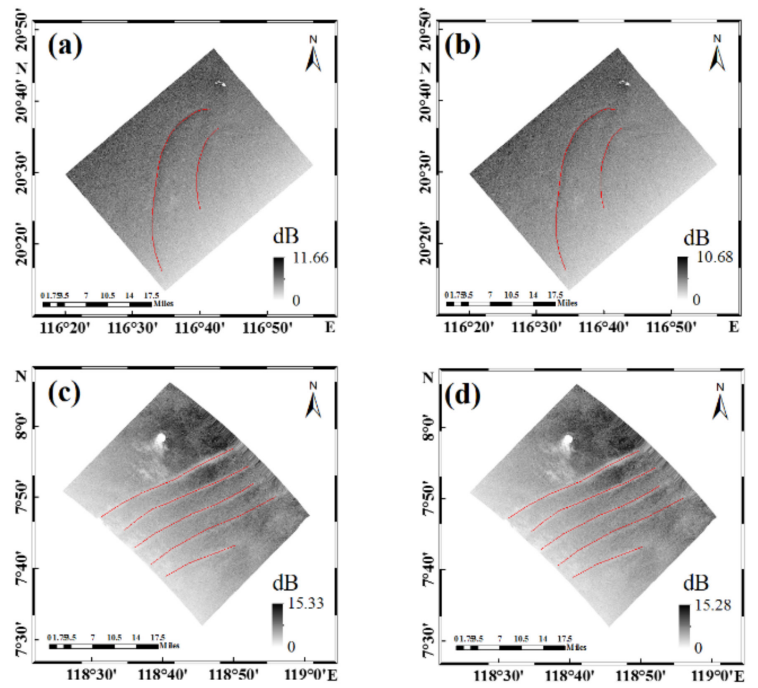

Figure 2. Examples of InIRA images obtained by Tiangong-2, the red solid lines are the crest lines of ISWs: (a,b) UTC 23 September 2016, South China Sea; (c,d) UTC 1 June 2018, Celebes Sea.

\section{Internal Solitary Waves Features Acquisition}

\subsection{Two-Dimensional Information on the Sea Surface of ISWs}

Whether InIRA can be used to detect oceanic ISWs is a problem that concerns many oceanographers. This section discusses the feasibility of using the L2 data of InIRA onboard Tiangong-2 to obtain information on the sea surface of ISWs. First, noise in the InIRA L2 product data is filtered, and image processing software such as ENVI is used to extract the ISW information from the images. Then, the characteristics of ISWs (including the length of the crest line, convergence and divergence phenomena, and the spatial distribution of ISWs) are analyzed and compared with the detection results of ISWs by traditional optical sensors.

\subsubsection{ISWs Crest Line Extraction}

As mentioned above, ISWs often exist in the form of wave packets composed of single or multiple solitons and appear in SAR images as bright and dark bands. These bright and dark bands represent convergence and divergence phenomena, respectively, caused by ISWs [15]. Therefore, ISWs should similarly appear in InIRA L2 images as single or multiple bands of light and dark.

Figure 3 shows six scenes displaying ISWs in InIRA L2 images, all of which were acquired in antenna 1 . The images are processed, the crest lines of the leading ISWs are extracted, and the lengths of these crest lines are used to understand the spatial scale of the influence of ISWs. In addition, profile information is obtained along the vertical direction of the leading waves, and the number and wavelength of solitons are obtained by using this profile information. The red solid lines in these images are the crest lines of the leading ISWs.

Figure 3a shows the characteristics of ISWs in the Andaman Sea. The image, which was acquired on 9 September 2018 (UTC), contains three sets of relatively obvious ISW packets. The upper two sets of wave packets contain more than five solitons, and the length of the leading wave crest line reaches $20 \mathrm{~km}$; however, the bottom wave packet is not fully displayed due to the limited swath width. Figure $3 b, c$ present images of ISWs in SCS. Figure $3 \mathrm{~b}$ captures two sets of wave packets. The distance between the solitons in either wave packet is relatively small, although the image does not fully show the ISW system. Nevertheless, the image reveals that the spatial scale of ISWs is large, and the length of the crest line is $35 \mathrm{~km}$. Figure $3 \mathrm{c}$ depicts five relatively obvious solitons propagating northwestward; the average distance between the solitons is $5 \mathrm{~km}$, and the length of the leading wave crest line is approximately $42 \mathrm{~km}$. Figure $3 \mathrm{~d}$ shows an image of 
ISWs in the Sea of Japan featuring complex structures and varying propagation directions. The characteristics of the ISWs in this figure also conform to the above characteristics, and it is clear that the ISWs interact with each other and that their propagation directions intersect. The characteristics of ISWs in the Celebes Sea and the waters near the Yangtze River estuary are shown in Figure 3e,f, respectively. The ISWs outside the Yangtze River estuary are particularly significant, with multiple sets of ISWs propagating eastward in the image. The outermost wave packet contains six to ten solitons, and the length of the crest line reaches $40 \mathrm{~km}$. In addition, due to the bathymetry, the solitons at both ends of the wave packet propagate faster, while those in the middle propagate more slowly, resulting in a phenomenon known as stacking in the middle. As these images show, InIRA can reliably acquire the surface information of ISWs ranging from single-soliton ISWs with simple structures to multi-soliton packet systems with complex structures.

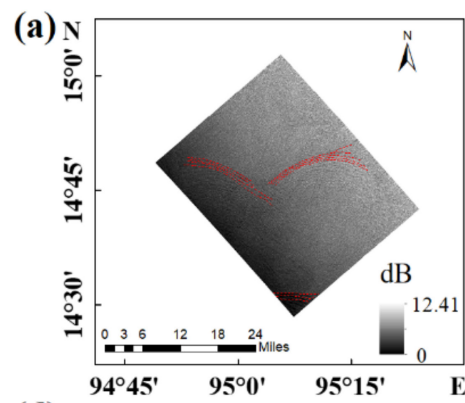

(d)

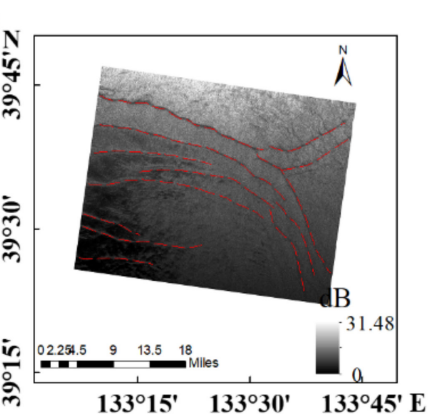

(b)

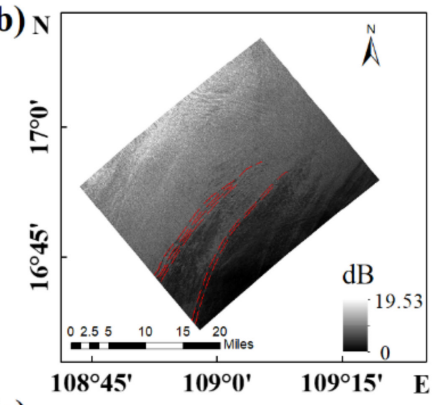

(e)

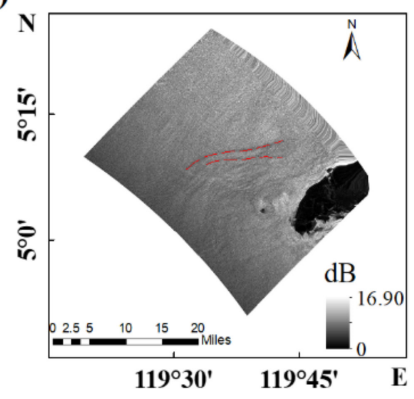

(c)

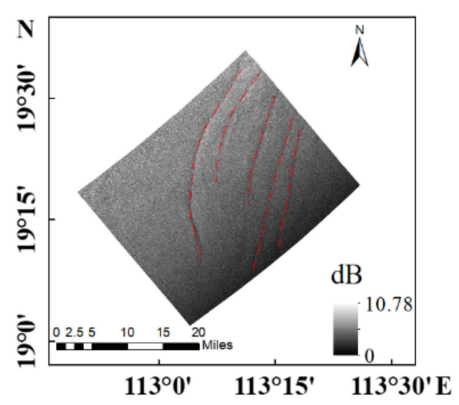

(f)

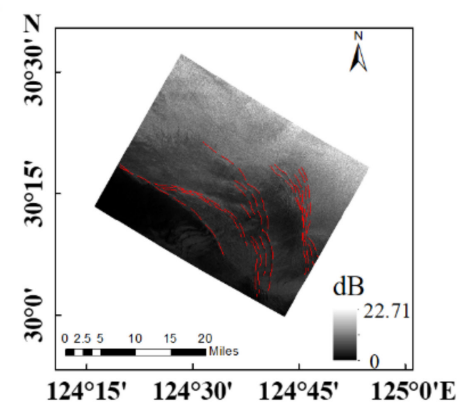

Figure 3. Images of ISWs from InIRA onboard Tiangong-2, where the red solid lines are the crest lines of the leading ISWs: (a) Andaman Sea, 9 September 2018 UTC; (b) SCS, 30 May 2018 UTC; (c) SCS, 8 June 2018 UTC; (d) Sea of Japan, 23 September 2016 UTC; (e) Celebes Sea, 17 April 2018 UTC; (f) waters near the Yangtze River Estuary, 7 April 2019 UTC.

In addition, 78 InIRA L2 images of ISWs in the Sea of Japan were acquired and processed; then, the crest lines of the ISWs were extracted, and whether these data can be used to further analyze the spatial distribution characteristics of ISWs was explored. Figure 4 shows the spatial distribution characteristics of the ISWs in the Sea of Japan. The red solid lines in Figure 4 delineate the crest lines of the ISWs extracted from the InIRA images, while the gray solid lines signify ISWs obtained from Moderate Resolution Imaging Spectroradiometer (MODIS) images from 2015 to 2019. The water depth data are from ETOPO1. An analysis of the MODIS results shows that the ISWs in the Sea of Japan are distributed mainly in the deep-sea basin and the Tsushima Strait on the northeast side of Jeju Island. In addition, the ISWs in this sea area exhibit very complex structural features, with many sources and multidirectional propagation paths. The lengths of the crest lines of the leading ISWs vary from a few kilometers to a hundred kilometers. The spatial distribution of InIRA-imaged ISWs in the Sea of Japan conforms to the same characteristics as those obtained by MODIS. The spatial scale of these ISWs is small, and their propagation directions intersect. Conversely, the locations at which these ISWs mainly occur are consistent with the MODIS results. However, due to the download limit on InIRA data, it is impossible to fully describe the characteristics of ISWs in this 
area. Nevertheless, these analyses demonstrate the potential of InIRA in obtaining surface information from ISWs.

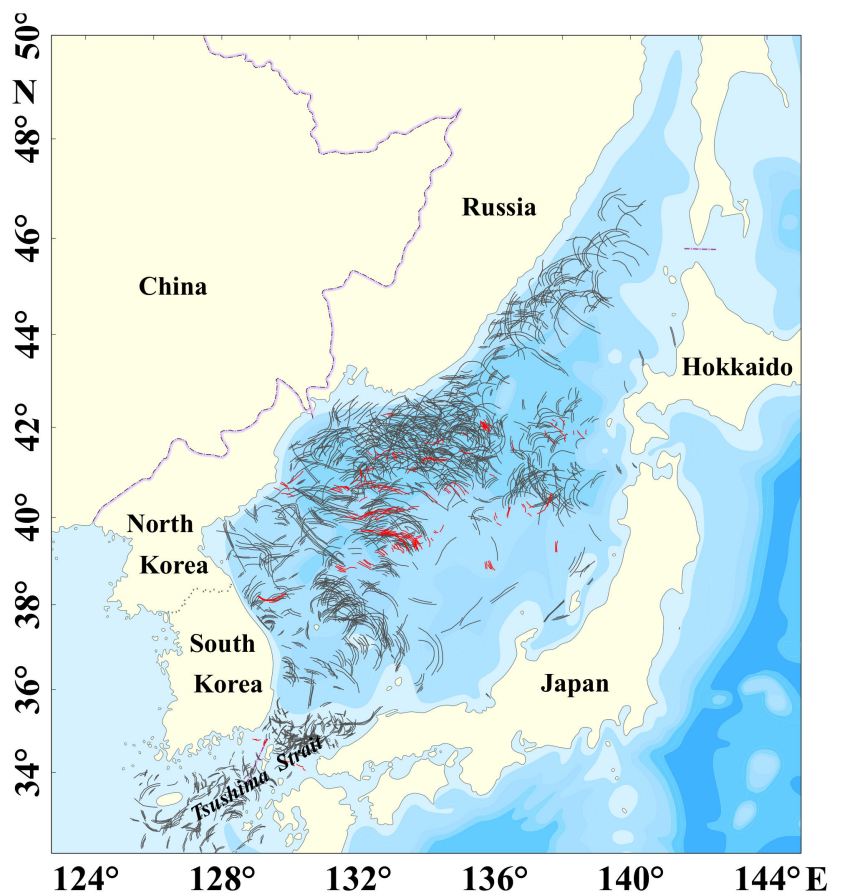

Figure 4. Map of the spatial distribution characteristics of ISW crest lines in the Sea of Japan. The gray solid lines are the MODIS image extraction results, while the red solid lines are the InIRA image extraction results.

\subsubsection{Contrast with Optical Remote Sensing Images}

Optical remote sensing is commonly employed in the research and detection of ISWs. The advantages of optical sensors are a large swath width and high temporal resolution. To analyze the reliability of InIRA onboard Tiangong- 2 as a new type of sensor in the acquisition of ISW surface information, this section compares the differences between InIRA and MODIS, a traditional optical remote sensing instrument.

MODIS has a swath width of $2330 \mathrm{~km}$ and can provide data with spatial resolutions of 1000,500 , and $250 \mathrm{~m}$. Due to its advantages, such as its long on-orbit time, high data quality, and free public data access, MODIS has been widely used to track the sources, investigate the temporal and spatial distribution characteristics, and invert the parameters of ISWs [5,41,42]. Figure 5 shows the characteristics of ISWs near Dongsha Island in SCS on 12 August 2017. The upper-left panel presents a relatively cloudy and foggy MODIS image with a spatial resolution of $250 \mathrm{~m}$ acquired at 03:10 UTC on 12 August 2017, covering almost the entire northern sector of the SCS. The image on the right was taken by InIRA at 14:10 UTC on 12 August 2017, and it covers only a small area. Figure 5c shows the superposed crest lines of the ISWs extracted from the two images. The red solid lines are the crest lines of the ISWs from the MODIS image, the blue dashed lines correspond to those of the ISWs from the InIRA image, and the gray box represents the area with the same ISWs obtained from the two images. The ISWs information obtained by the two sensors is quite different. The MODIS image contains four sets of relatively obvious ISWs packets (represented by ISW-1 ISW-4). These ISWs were generated in the Luzon Strait, after which they propagated westward and encountered DongSha Island; these ISWs were then refracted, and the single soliton became an ordered wave packet. The InIRA image detected only the easternmost single soliton which Figure $5 \mathrm{c}$ shows was located near the upper-right corner of ISWS-1 in the MODIS image. This confirms that the ISW features identified from the InIRA image are reliable. 

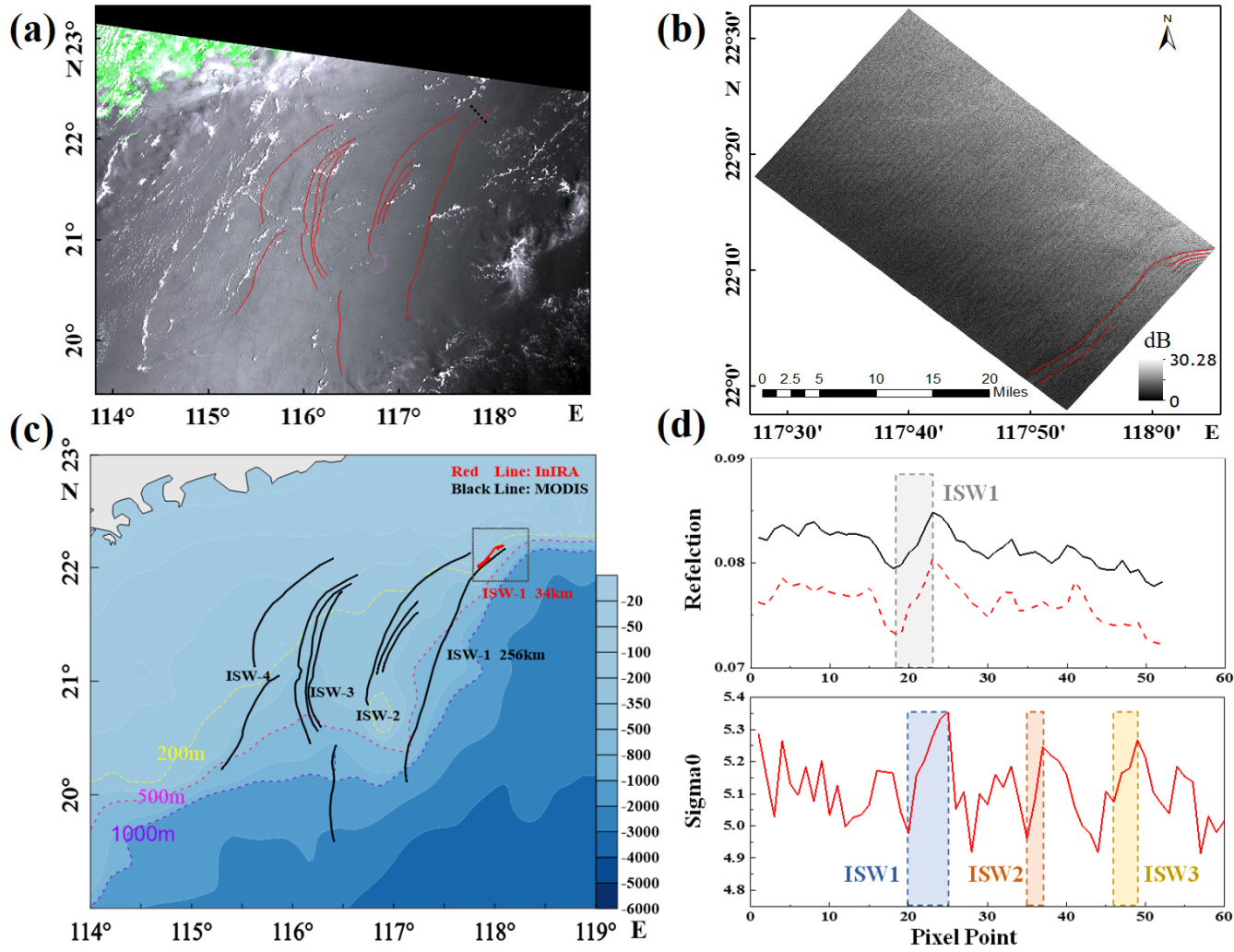

Figure 5. Comparison of the abilities of InIRA and MODIS to detect ISWs. (a) MODIS image acquired at 03:10 UTC on 12 August 2017; the crest lines are shown as red solid lines. (b) InIRA image acquired at 14:18 UTC on 12 August 2017. (c) ISWs from the two images superposed; the black (red) solid lines are the crest lines of the ISWs from the MODIS (InIRA) image. The number of the ISW is represented by "ISWS-X" (X being the number from 1 to 4), the gray box is the overlapping area between the two images, and the colored dashed lines are water depth contours. (d) Profiles drawn along the vertical direction of the ISW crest line (black dashed line in Figure 5a,b); the upper (lower) panel is from the MODIS (InIRA) data.

Furthermore, the characteristics of the ISWs in the gray box are slightly different. The positions of the ISW crest lines are not completely superimposed. This is because there is an 11-h interval between the two; therefore, the ISWs in the image are not the same. However, considering that the characteristics of ISWs in this area are very stable, they can still be compared and analyzed. Second, the leading wave in the InIRA image is followed by 2-3 small solitons, while the MODIS image identifies only the leading wave, reflecting the advantageously high spatial resolution of InIRA, which can detect more detailed features of ISWs. However, due to the imaging quality of InIRA, the shapes of the following solitons in the InIRA image are not fully detected. In addition, the numbers in Figure $5 \mathrm{c}$ are the crest line lengths of overlapping ISWs in the two scenes ( 34 and $256 \mathrm{~km}$, respectively). These results show that the spatial scale of ISWs in the InIRA image is only approximately $13 \%$ of the spatial scale of those in the MODIS image, indicating that the swath width of InIRA has a significant inhibitory effect on the detection of ISWs.

A section along the vertical direction of ISWs crest in the SAR image is drawn, and the profile curve will show a sawtooth undulation, where the highest point represents the convergence zone of ISWs, and the lowest point represents the divergence zone of that. Therefore, ISWs position can be determined according to the highest point and the lowest point in the profile. Figure $5 \mathrm{~d}$ shows the ISWs profiles extracted along the vertical direction of the crest line (the black dashed line in Figure 5a). The solid and dashed lines in the MODIS processing results represent the information of the two bands, and the vertical axis is the reflectance value. The results of the two channels can be used to identify a relatively 
obvious soliton that first presents as a dark band and then as a bright band, and the spacing between the bright and dark bands is six pixels. The InIRA L2 data model is similar to SAR insomuch that it has only a single channel of information, three soliton profiles can be identified in the image, and the model still exhibits first a dark band and then a bright band. This finding further demonstrates the advantages of the high spatial resolution of InIRA, which can thus identify more information than MODIS.

\subsection{SSHA Caused by ISWs}

An imaging altimeter is essentially a sensor that obtains the height of the target. Although SAR imaging and interferogram processing are components of imaging altimetry and data processing, the elevation information is its most important contribution. Specifically, the InIRA instrument onboard Tiangong-2 can distribute L4 data with elevation information, with a spatial resolution of $40 \mathrm{~m}$. Studies have shown that the propagation of ISWs causes vertical fluctuations in the sea surface. Therefore, accurately obtaining the relative height changes of the sea surface caused by ISWs is a major oceanographic research direction. This section analyzes whether InIRA L4 data can be used to obtain the sea surface height changes caused by ISWs. First, the positions of ISWs in L2 images are located, and then the SSHA at the corresponding positions in L4 images are analyzed.

Figure 6a,b shows examples of an image of the SCS obtained on 23 September 2016. The ISWs propagates northwestward in the form of a single soliton (marked by the red circle). Using ArcGIS software, the crest length of ISW obtained from the image is $45 \mathrm{~km}$. InIRA L2 image is similar to SAR, and all acquired are NRCS. Therefore, it can be based on conventional SAR image inversion method of ISWs parameters (such as KdV equation [15]), using InIRA L2 image for ISWs amplitude inversion. In addition, the amplitude of this soliton calculated by $\mathrm{KdV}$ equation is about $55 \mathrm{~m}$. The solid blue line is the propagation direction of ISWs, the yellow dashed line is the direction of travel of Tiangong-2, and the geometric relationship between the two is not vertical. The L4 image also reveals similar ISW characteristics, as shown in the red dashed box in Figure 6b. The SSHA in the vicinity of the ISW soliton is approximately $13 \mathrm{~m}$, which is approximately $40 \mathrm{~cm}$ different from the surrounding uniform sea surface, showing an instantaneous decline. The changes in SSHA caused by ISWs in this example provided above are all on the order of centimeters, which is consistent with the conclusions of previous research $[27,28]$. However, the second soliton was not found in the L4 image. The article believes that the reason for this problem is that compared with the first soliton, its energy is smaller. The SSHA caused by it is small compared with the relative measurement accuracy of the InIRA height product $(20 \mathrm{~cm})$; thus, it is difficult to be detected.
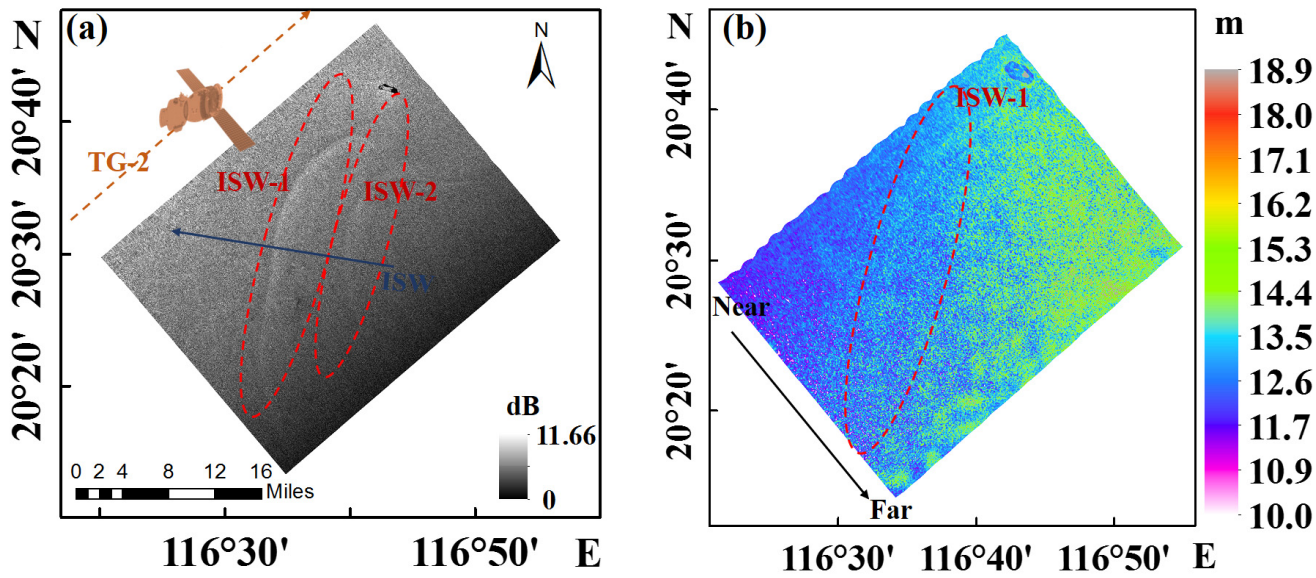

Figure 6. The InIRA images featuring ISWs acquired in SCS on 23 September 2016: (a) L2 image, the blue solid lines signify the propagation direction of ISWs, while the yellow dashed lines show the flight direction of Tiangong-2; (b) L4 image, ISWs features are in the red circle. 
In addition, in the near-nadir point area in Figure $6 b$, the edge of the image is jagged. The reason for this problem is that the imaging altimeter needs to match and align the echo signals emitted and received at different times during the imaging process to eliminate noise interference at near-nadir points; thus, irregular jagged phenomena are generated.

Figure 7 shows the characteristics of ISWs in the Sea of Japan. The image was acquired on 23 September 2016. At least four obvious ISWs propagating northeastward can be found in the image, and they interact with each other. The red box in Figure 7a marks two solitons, and they are also be founded in L4 image. Interpreting the image shows that the SSHA caused by the ISWs is about $0.4 \mathrm{~m}$. Similar to Figure 6, in Figure 7b, some ISWs features are missing. The reason is still that the relative measurement accuracy of InIRA height product images is low.

(a)

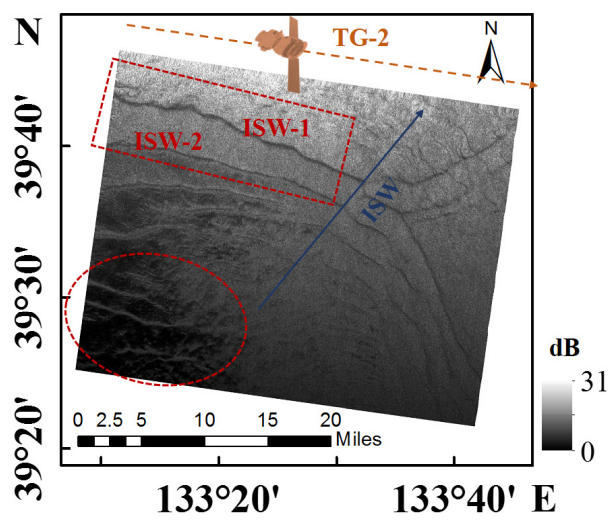

(b)
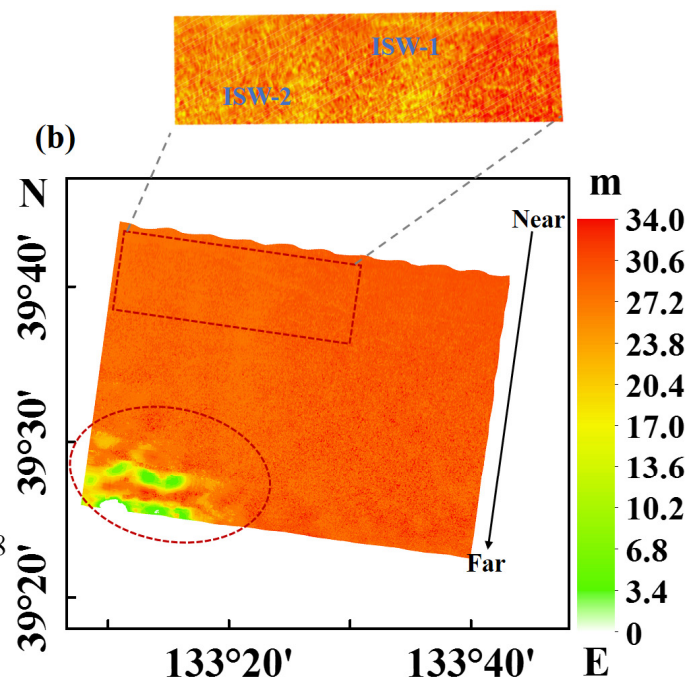

Figure 7. The InIRA images featuring ISWs acquired in the Sea of Japan on 23 September 2016: (a) L2 image, the blue solid lines signify the propagation direction of ISWs, while the yellow dashed lines show the flight direction of Tiangong-2; (b) L4 image, ISWs features are in the red box, and the red circle is the abnormal data.

In addition, an abnormal phenomenon is marked in the red circle in Figure 7 . In the $\sigma \_0$ image, there are ISWs features inside this round frame, but in the L4 image, the value in this area is different from the surroundings by tens of meters. This is seriously beyond the range of SSHA caused by internal solitary waves. The reason for this problem may be that the echo energy at the far nadir point of the InIRA image is small, the signal noise ratio (SNR) is poor, and the phase difference obtained from the main and auxiliary images is pseudo-amplified, which results in a large calculation deviation. This article often encounters this problem when processing other L4 images, which requires correction of the image processing algorithm.

Due to the limitation of data distribution, this article does not show other specific examples of SSHA caused by ISWs. Nevertheless, the analysis from Figures 6 and 7 shows that InIRA L4 data can detect the SSHA caused by oceanic ISWs, which provides a new perspective for further research on the ocean dynamics of ISWs.

In addition, the analysis by Santos-Ferreira et al. showed that in synthetic aperture radar altimeters, there is a significant correlation between the normalized radar cross section (NRCS) and sea surface height (SSH) at the sea surface where ISWs act. Therefore, this article quantitatively compared InIRA L2 images (NRCS) and L4 images (SSHA) to analyze whether there is a certain relationship. Specifically, for the same ISW, obtain the NRCS profile and the SSHA profile along the propagation direction of its crest line to further analyze. However, the results did not show a more convincing law. Due to limited 
data, we cannot draw conclusions on this; however, we doubt whether this is caused by InIRA's system parameters (such as low signal noise ratio).

\section{Discussion}

\subsection{Image Coverage}

As shown during the analysis in Chapter 3, the swath width of InIRA is only $30 \mathrm{~km}$, which is much smaller than the spatial scale of ISWs in the ocean (almost $100 \mathrm{~km}$ ) [43]; therefore, complete information on ISWs cannot be obtained using InIRA alone. However, the Tiangong-2 InIRA instrument can obtain on-orbit information on a longer spatial scale when shooting, but this information is divided into multiple independent sub-images during data processing. Therefore, in this article, the continuous images acquired by InIRA are stitched together to broaden the coverage in the azimuth direction. Figure 8 shows four InIRA L2 images taken in the Sea of Japan with significant ISW characteristics. The ISWs in these images propagate from south to north. As indicated by the image information in Table 1, all four images were acquired on the same track, as their orbit data numbers are all " 7 ", and the image data numbers are "52-55".

(a)

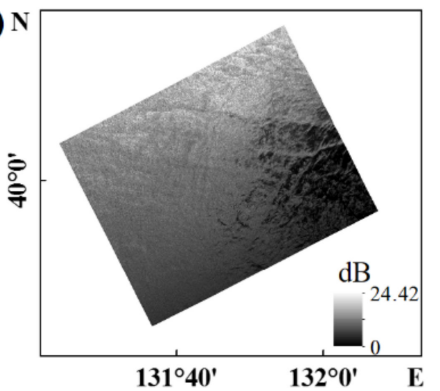

(c)

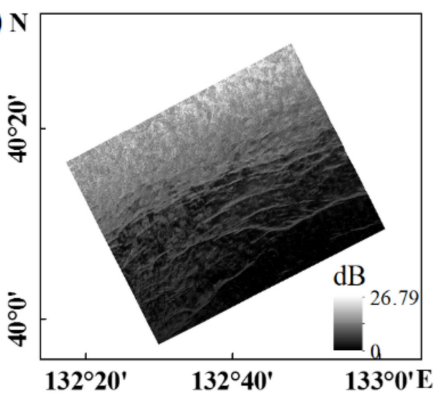

(b)

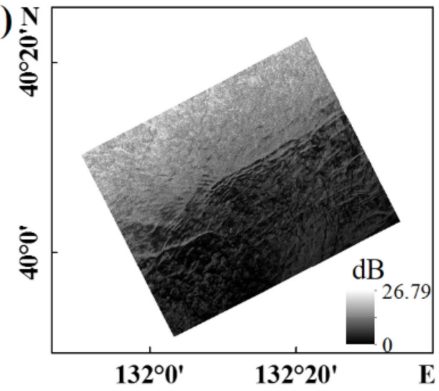

(d)

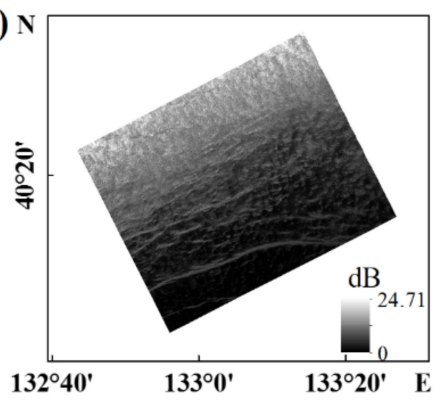

Figure 8. InIRA images of the ISWs in the Sea of Japan acquired from the same orbit at 13:15 on 23 September 2016, where panels (a-d) correspond to image data numbers of 52 through 55, respectively.

Table 1. InIRA images of the ISWs in the Sea of Japan.

\begin{tabular}{ccc}
\hline Number & Image Information & Image Center \\
\hline \multirow{2}{*}{1} & T2_IALT_RIM1_SCI_20160923131510_20160923133009 & $131.8704^{\circ} \mathrm{E}$ \\
& _L2_7_52_20181017215017_V200 & $39.9469^{\circ} \mathrm{N}$ \\
\hline \multirow{2}{*}{2} & T2_IALT_RIM1_SCI_20160923131510_20160923133009 & $132.2892^{\circ} \mathrm{E}$ \\
& _L2_7_53_20181017220822_V200 & $40.0315^{\circ} \mathrm{N}$ \\
\hline \multirow{2}{*}{3} & T2_IALT_RIM1_SCI_20160923131510_20160923133009 & $132.7357^{\circ} \mathrm{E}$ \\
& _L2_7_54_20181017222423_V200 & $40.1357^{\circ} \mathrm{N}$ \\
\hline \multirow{2}{*}{4} & T2_IALT_RIM1_SCI_20160923131510_20160923133009 & $133.1813^{\circ} \mathrm{E}$ \\
& _L2_7_55_20181017224126_V200 & $40.2369^{\circ} \mathrm{N}$ \\
\hline
\end{tabular}

The four groups of continuously shot images in Figure 8 are stitched together to expand the spatial coverage of InIRA. Figure 9 shows the gratifying result. The stitched 
image significantly increases the dimension of the image in the azimuthal direction: nearly $200 \mathrm{~km}$ of information can be obtained along the flight direction of the aircraft. Although it is impossible to broaden the range coverage by similar methods, splicing in the azimuthal direction can yield more complete ISW shape information. As shown in Figure 8, the length of the leading wave crest line is $110 \mathrm{~km}$, far exceeding the swath width $(30 \mathrm{~km})$ of a single InIRA L2 image.

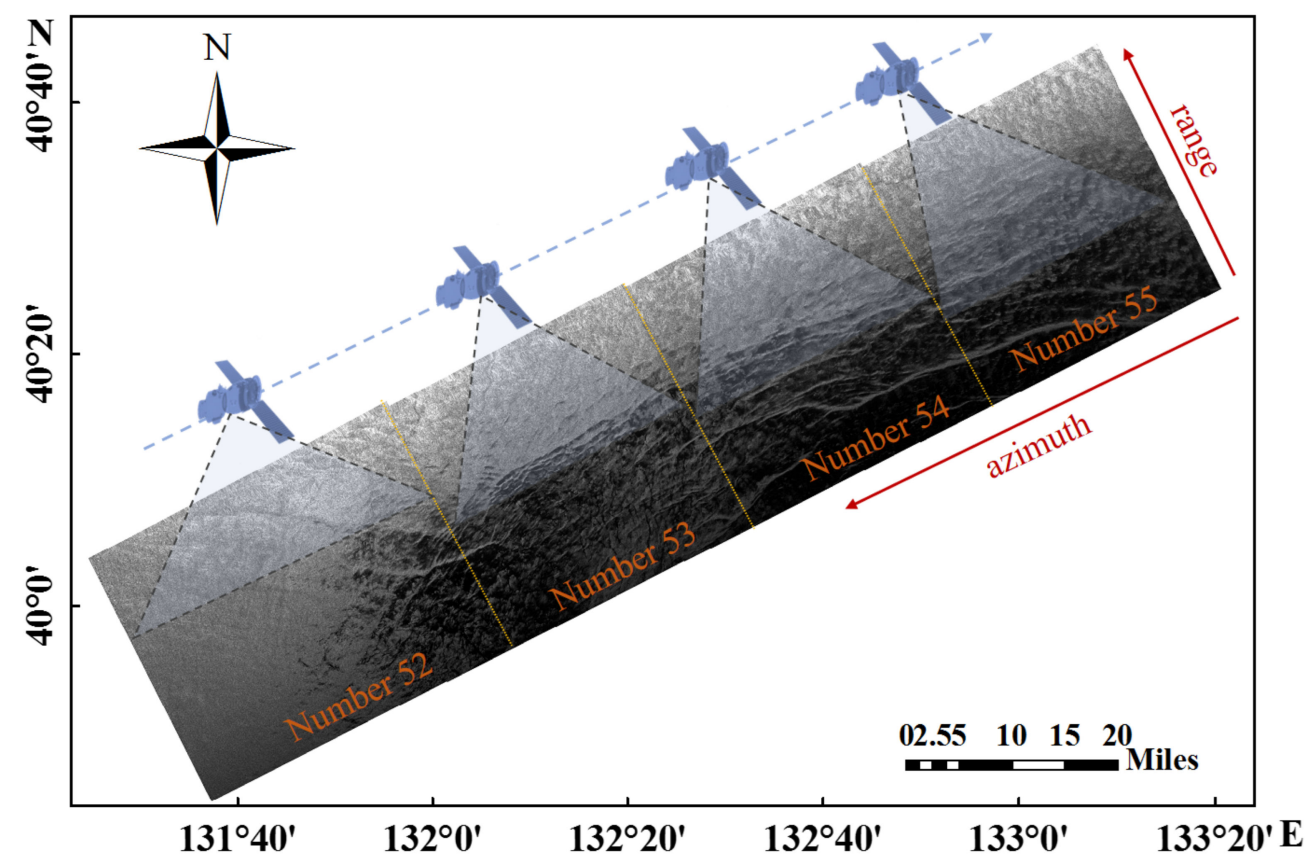

Figure 9. The resulting image of the stitching of the images in Figure 7. The image data numbers are $52-55$, and the blue dashed line represents the flight direction of Tiangong-2.

Although the azimuthal coverage of InIRA images can be broadened through data postprocessing, as shown above, additional information cannot be obtained in the range direction. This is likely limited predominantly by the incident angle range and platform height of InIRA. As shown in Table 2, compared to traditional imaging sensors, the incident angle range $\left(2.5-7.5^{\circ}\right)$ and lower platform height $(380 \mathrm{~km})$ of InIRA limit its swath width. Therefore, to obtain more information, it is necessary to program the platform to make multiple observations of a certain ISW hot spot. This emphasizes a perspective for the subsequent development of imaging altimeters, that is, to broaden the range of incident angles and increase the altitude of the platform to increase the range width and to simultaneously perform larger-scale SAR data processing to improve the azimuthal image dimension.

Table 2. Setting the parameters of the imaging sensor.

\begin{tabular}{ccccc}
\hline Satellite/Platform & Sensor/Data & $\begin{array}{c}\text { Platform } \\
\text { Height/Km }\end{array}$ & $\begin{array}{c}\text { Incident Angle } \\
\text { Range/ }\end{array}$ & $\begin{array}{c}\text { Image } \\
\text { Width/Km }\end{array}$ \\
\hline TIANGONG-2 & InIRA & 380 & $2.5-7.5$ & 30 \\
\hline GF-3 & QPSI & 755 & $20-40$ & $30-40$ \\
\hline ALOS-2 & StripMap & 628 & $8-30$ & $50-70$ \\
\hline Sentinel-1 & StripMap & 700 & $20-45$ & 80 \\
\hline TerraSAR-X & StripMap & 515 & $20-45$ & $30-50$ \\
\hline RADARSAT-2 & Standard & 798 & $20-52$ & 100 \\
\hline
\end{tabular}




\subsection{Height Data Acquisition}

The propagation of ISWs triggers changes in the sea surface height, which can theoretically be detected with an altimeter. In addition, da Silva et al. used traditional altimeters and SARL to research the sea surface height changes caused by ISWs and pointed out that the change information obtained by the sensor is most significant when the ISW propagation direction and altimeter trajectory are perpendicular to each other $[27,29,31,44,45]$. However, this article reports that imaging altimeters can obtain not only the characteristics of the SSHA caused by ISWs propagating perpendicular to the sensor track but also the characteristics of the SSHA parallel to the sensor trajectory, as shown in Figure 7. This outcome is the result of the working mode of the imaging altimeter.

Different from the vertical observation of the nadir point of a traditional altimeter, an imaging altimeter adopts the interferometric mode of side-looking dual-antenna observation. InIRA uses two antennas (A1 and A2) with a spacing of $2.3 \mathrm{~m}$ to simultaneously observe the sea area. One of these antennas emits spherical pulsed electromagnetic waves toward the sea surface at a certain angle of incidence. After these electromagnetic waves reach the sea surface, they are reflected and return to the two antennas to generate complex images containing both amplitude information and phase information. Afterward, during interferogram processing, according to the phase difference between the echoes received by antennas $\mathrm{A} 1$ and $\mathrm{A} 2$, the geometric observation angle from the antenna to the target, the baseline length, etc., the two complex images are converted into elevation information products that reflect relative height changes [34].

Figure 10 depicts a schematic diagram of the oceanic ISWs observed by InIRA onboard Tiangong-2. A1 and A2 are the left and right antennas, respectively. R1 and R2 are the slant distances from observation point $\mathrm{P}$ to $\mathrm{A} 1$ and $\mathrm{A} 2$, respectively. $\mathrm{B}$ is the baseline distance, $\alpha$ is the baseline inclination, $\theta$ is the geometric observation angle of antenna A1, $\lambda$ is the $\mathrm{Ku}$-band wavelength, and $\mathrm{H}$ is the satellite orbit height. Then, the relative change height $h$ of a certain point on the sea surface caused by ISWs can be expressed by the following formula [46]:

$$
h=H-R_{1} \cos \theta=H-R_{1} \cos \left[\alpha-\arcsin \left(\frac{\lambda \phi}{2 \pi n B}\right)\right]
$$

where $n$ is the spatially averaged multi-look number and $\phi$ is the echo phase difference the two antennas, $\phi=\phi_{1}-\phi_{1}=\frac{2 \pi\left(R_{1}-R_{2}\right)}{\lambda}$. Therefore, in theory, as long as the observation area contains height fluctuations, InIRA can record a phase difference containing information on the height change of the sea surface. As shown by the red curve in Figure 10, during their propagation, ISWs produce upward and downward displacements of the sea surface in the convergence zone and the divergence zone, respectively, causing the sea surface to fluctuate. Therefore, an imaging altimeter can observe ISWs propagating in any direction and does not need to consider the geometric relationship between the sensor's flight direction and the propagation direction of ISWs.

In addition, the use of InIRA images to carry out wind field $[35,36]$ and significant wave height [40] and other environmental variables inversion research has been widely carried out. At the same time, environmental variables such as wind and sea conditions may affect the accuracy of InIRA's detection on ISWs. For example, Li et al. have proved that the wind will affect the SAR imaging of ISWs [47]. However, this paper only initially analyzed the potential of InIRA to detect ISWs. Regarding the influence of wind or other variables on horizontal and vertical motions of ISWs obtained by imaging altimeter, further qualitative and quantitative analysis is needed, such as using the SWOT satellite data released in 2022. 


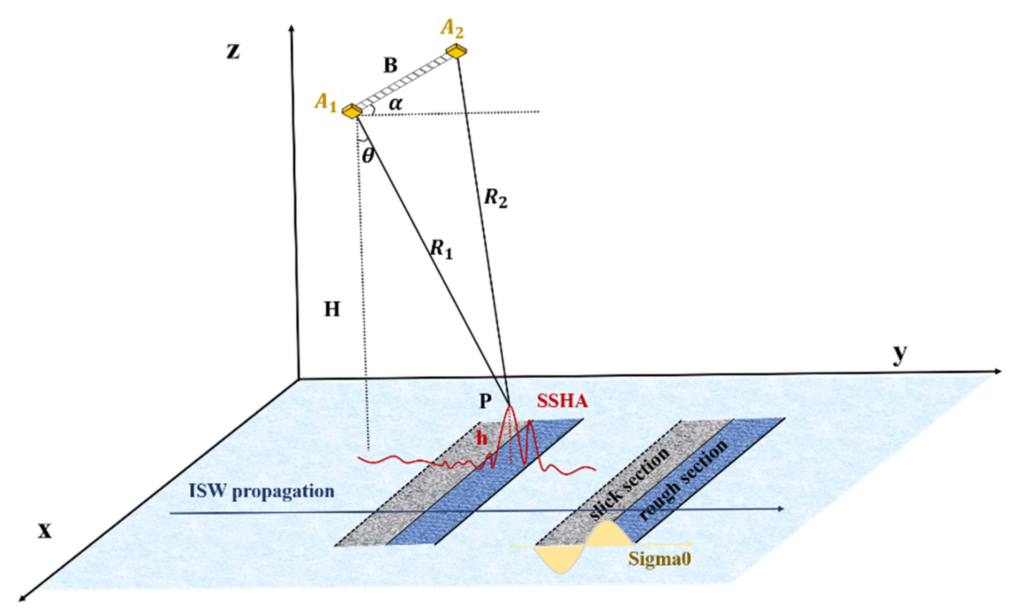

Figure 10. Schematic diagram of ISWS observed by InIRA on Tiangong-2.

\section{Summary}

As the newest-generation type of altimeter, imaging altimeters have tremendous application potential in monitoring ocean targets, analyzing ocean phenomena, and revealing ocean activities, but many research gaps have yet to be filled. This article focuses on the characteristics of imaging altimeters with regard to research on the detection of internal solitary waves (ISWs) in the ocean. The Interferometric Imaging Radar Altimeter (InIRA) carried by China's Tiangong-2 space laboratory (Tiangong-2) launched on 15 September 2016, is the first operating imaging altimeter in the world. InIRA has a baseline distance of $2.3 \mathrm{~m}$ and an incident angle range of $2.5-7.5^{\circ}$, and it can provide two scenes, namely, main and auxiliary channel images, at the same time. At present, the public can submit an application to download some of the data obtained by InIRA.

Based on Tiangong-2 InIRA L2 and L4 images, this paper analyzes the feasibility of employing InIRA data to study oceanic ISWs. The results show that as a new type of sensor, InIRA demonstrates a relatively reliable ability to observe ISWs and thus can be utilized to detect and identify different types of ISWs, such as single solitons with simple structures and multi-soliton packet systems with complex structures. The spatial distribution characteristics of ISWs in the Sea of Japan using these data are also consistent with those obtained from the processing of MODIS data. Comparing InIRA imagery with MODIS imagery reveals that the former can identify smaller ISWs features than the latter, demonstrating the advantage of the high spatial resolution of InIRA.

Through the image processing of height products, the characteristics of the sea surface height changes caused by ISWs can be observed with InIRA. The results of the examples presented in this article show that the SSHA induced by ISWs are on the order of centimeters. Moreover, the geometric relationship between the sensor's flight direction and the propagation direction of ISWs is not an important factor in obtaining SSHA changes caused by ISWs. However, the quantitative relationship between InIRA L2 images (NRCS) and L4 images (SSHA) requires further analysis. In addition, research on the influence of wind field or other environmental variables on the acquisition of ISWs characteristics may be further carried out.

Although InIRA has demonstrated a highly advantageous ability to detect ISWs, this instrument still suffers from some shortcomings. First, the swath width of InIRA is only $30 \mathrm{~km}$, which is much smaller than the spatial scale of mesoscale ocean phenomena. The results of processing an image obtained on 12 August 2017 show that the crest line length of the ISWs in the InIRA image is only 13\% of that in the MODIS image; hence, the acquisition of ISW information by InIRA is incomplete. However, this article demonstrates that the splicing method can be used to broaden the azimuthal coverage of InIRA images, and the swath width in the range direction needs to increase the incidence angle and raise the operating height of the platform to achieve widening. Second, the relative measurement 
accuracy of InIRA height images is low, and it is impossible to detect the height information of ISWs in small scales. This needs to improve its measurement accuracy in the future development of imaging altimeters to achieve centimeter-level measurement. In addition, due to the limitation of data processing methods, jagged edges will appear at the near nadir end of the height image, and serious height measurement errors will appear at the far nadir end.

In summary, this article discusses the feasibility of employing imaging altimeters to obtain two-dimensional information of oceanic ISWs and vertical sea surface height information, but the application potential of imaging altimeters needs to be further developed. The vertical structural characteristics of ISWs can be analyzed in detail based on the existing work, such as the relationship between SSHA and their amplitude; image processing can also improve the image quality of imaging altimeters. Joint observational research with other satellite sensors to further reveal the characteristics of ocean phenomena is the goal of all oceanographers.

Author Contributions: J.M. provided the conceptualization and revised the manuscript. H.Z. developed the methodology, performed the experiments and analysis, and wrote the manuscript. C.F. and S.L. discussed the analysis and revised the manuscript. L.S. revised the manuscript. All authors have read and agreed to the published version of the manuscript.

Funding: This research was funded by the National Natural Science Foundation of China (No. U2006207), the National Natural Science Foundation of China (No. 42006164).

Institutional Review Board Statement: Not applicable.

Informed Consent Statement: Not applicable.

Data Availability Statement: Regarding the application and sharing of the data used in this article, you are welcome to contact Hao Zhang (zhanghao@fio.org.cn).

Acknowledgments: The authors would like to thank the China Manned Space Engineering for providing Interferometric imaging radar altimeter data products of Tiangong-2. Website: http: //www.msadc.cn/main/home.

Conflicts of Interest: The authors declare no conflict of interest.

\section{References}

1. Gerkema, T.; Zimmerman, J. An Introduction to Internal Waves; Lecture Notes; Royal NIOZ: Texel, The Netherlands, 2008; pp. 12-14.

2. Huang, X.D.; Chen, Z.H.; Zhao, W.; Zhang, Z.W.; Zhou, C.; Yang, Q.X.; Tian, J.W. An extreme internal solitary wave event observed in the northern South China Sea. Sci. Rep. 2016, 6, 30041. [CrossRef] [PubMed]

3. Ramp, S.R.; Tang, T.Y.; Duda, T.F.; Lynch, J.F.; Liu, A.K.; Chiu, C.-S.; Bahr, F.L.; Kim, H.-R.; Yang, Y.-J. Internal solitons in the northeastern South China Sea. Part I: Sources and deep water propagation. IEEE J. Oceanic. Eng. 2004, 29, 1157-1181. [CrossRef]

4. Bai, X.L.; Liu, Z.Y.; Li, X.F.; Chen, Z.Z.; Hu, J.Y.; Sun, Z.Y.; Zhu, J. Observations of high-frequency internal waves in the southern Taiwan Strait. J. Coastal. Res. 2013, 29, 1413-1419. [CrossRef]

5. Jackson, C. Internal wave detection using the Moderate Resolution Imaging Spectroradiometer (MODIS). J. Geophys. Res. Oceans 2007, 112, 4220-4239. [CrossRef]

6. Zheng, Q.A.; Susanto, R.D.; Ho, C.-R.; Song, Y.T.; Xu, Q. Statistical and dynamical analyses of generation mechanisms of solitary internal waves in the northern South China Sea. J. Geophys. Res. Oceans 2007, 112, C03021. [CrossRef]

7. Sun, L.N.; Zhang, J.; Meng, J.M. A study of the spatial-temporal distribution and propagation characteristics of internal waves in the Andaman Sea using MODIS. Acta Oceanol. Sin. 2019, 38, 121-128. [CrossRef]

8. Alpers, W.; Wang-Chen, H.; Hock, L. Observation of internal waves in the Andaman Sea by ERS SAR. In Proceedings of the IEEE International Geoscience and Remote Sensing Symposium Proceedings, Singapore, 3-8 August 1997; pp. 1518-1520. [CrossRef]

9. Schuler, D.L.; Jansen, R.W.; Lee, J.S.; Kasilingam, D. Polarisation orientation angle measurements of ocean internal waves and current fronts using polarimetric SAR. IEE P-Radar Son Nav. 2003, 150, 135-143. [CrossRef]

10. Karang, I.W.G.A.; Nishio, F. Internal waves in the Lombok Strait revealed by ALOS PALSAR images. In Proceedings of the 2011 IEEE International Geoscience and Remote Sensing Symposium, Vancouver, BC, Canada, 24-29 July 2011; pp. 253-256. [CrossRef]

11. Kozlov, I.; Romanenkov, D.; Zimin, A.; Chapron, B. SAR observing large-scale nonlinear internal waves in the White Sea. Remote Sens. Environ. 2014, 147, 99-107. [CrossRef]

12. Zhang, J.; Zhang, X.; Fan, C.Q.; Meng, J.M. Discussion on application of polarimetric synthetic aperture radar in marine surveillance. J. Radars. 2016, 5, 596-606. [CrossRef] 
13. Kozlov, I.E.; Zubkova, E.V.; Kudryavtsev, V.N. Internal solitary waves in the Laptev Sea: First results of spaceborne SAR observations. IEEE Geosci. Remote Sens. Lett. 2017, 14, 2047-2051. [CrossRef]

14. Ning, J.; Sun, L.N.; Cui, H.J.; Lu, K.X.; Wang, J. Study on characteristics of internal solitary waves in the Malacca Strait based on Sentinel-1 and GF-3 satellite SAR data. Acta Oceanol. Sin. 2020, 39, 151-156. [CrossRef]

15. Chong, J.S.; Zhou, X.Z. Survey of study on internal waves detection in synthetic aperture radar image. J. Radars. $2013,2,406-421$. [CrossRef]

16. Magalhaes, J.M.; da Silva, J.C.B. Satellite altimetry observations of large-scale internal solitary waves. IEEE Geosci. Remote Sens. Lett. 2017, 14, 534-538. [CrossRef]

17. Stammer, D. Global characteristics of ocean variability estimated from regional TOPEX/POSEIDON altimeter measurements. J. Phys. Oceanogr. 1997, 27, 1743-1769. [CrossRef]

18. Traon, P.Y.L.; Nadal, F.; Ducet, N. An improved mapping method of multisatellite altimeter data. J. Atmos. Ocean Technol. 1998, 15, 522-534. [CrossRef]

19. Nerem, R.S.; Chambers, D.P.; Choe, C.; Mitchum, G.T. Estimating mean sea level change from the TOPEX and Jason altimeter missions. Mar. Geod. 2010, 33, 435-446. [CrossRef]

20. Donlon, C.; Berruti, B.; Buongiorno, A.; Ferreira, M.-H.; Féménias, P.; Frerick, J.; Goryl, P.; Klein, U.; Laur, H.; Mavrocordatos, C.; et al. The global monitoring for environment and security (GMES) Sentinel-3 mission. Remote Sens. Environ. 2012, 120, 37-57. [CrossRef]

21. Ray, C.; Martin-Puig, C.; Clarizia, M.P.; Ruffini, G.; Dinardo, S.; Gommenginger, C.; Benveniste, J. SAR altimeter backscattered waveform model. IEEE Trans. Geosci. Remote Sens. 2015, 53, 911-919. [CrossRef]

22. Zhang, Y.H.; Jiang, J.S.; Zhang, H.Y.; Zhang, D.H. Spaceborne imaging altimeter for topographic mapping. In Proceedings of the IEEE 2000 International Geoscience and Remote Sensing Symposium, Honolulu, HI, USA, 24-28 July 2000; pp. 2349-2351. [CrossRef]

23. Dong, X.; Zhang, Y.H.; Zhai, W.S. Design and algorithms of the Tiangong-2 interferometric imaging radar altimeter processor. In Proceedings of the 2017 Progress In Electromagnetics Research Symposium—Spring (PIERS), St. Petersburg, Russia, 22-25 May 2017; pp. 3802-3803. [CrossRef]

24. Zhang, Y.H.; Shi, X.J.; Wang, H.J.; Tan, Y.Y.; Zhai, W.S.; Dong, X.; Kang, X.Y.; Yang, Q.S.; Li, D.; Jiang, J.S. Interferometric imaging radar altimeter on board Chinese Tiangong-2 space laboratory. In Proceedings of the 2018 Asia-Pacific Microwave Conference (APMC), Kyoto, Japan, 6-9 November 2018; pp. 851-853. [CrossRef]

25. Fu, L.-L.; Alsdorf, D.; Rodriguez, E.; Morrow, R.; Mognard, N.; Lambin, J.; Vaze, P.; Lafon, T. The SWOT (Surface Water and Ocean Topography) Mission: Spaceborne radar interferometry for oceanographic and hydrological applications. In Proceedings of the OceanObs'09: Sustained Ocean Observations and Information for Society, Venice, Italy, 21-25 September 2009.

26. Durand, M.; Fu, L.-L.; Lettenmaier, D.P.; Alsdorf, D.E.; Rodriguez, E.; Esteban-Fernandez, D. The Surface Water and Ocean Topography Mission: Observing terrestrial surface water and oceanic submesoscale eddies. Proc. IEEE 2010, 98, 766-779. [CrossRef]

27. Zhang, X.D.; Zhang, J.; Fan, C.Q.; Wang, J.; Meng, J.M. Observations of internal waves with high sampling data of radar altimetry and MODIS images. Int. J. Remote Sens. 2018, 39, 7405-7416. [CrossRef]

28. Santos-Ferreira, A.M.; da Silva, J.C.B.; Magalhaes, J.M. SAR mode altimetry observations of internal solitary waves in the tropical ocean Part 1: Case studies. Remote Sens. 2018, 10, 644-657. [CrossRef]

29. Zhang, X.D.; Zhang, J.; Meng, J.M.; Fan, C.Q.; Wang, J. Observation of internal waves with OLCI and SRAL on board Sentinel-3. Acta Oceanol. Sin. 2020, 39, 56-62. [CrossRef]

30. Santos-Ferreira, A.M.; da Silva, J.C.B. Can we retrieve internal soliton amplitudes in the ocean with SAR altimetry? What would this be good for? In Proceedings of the 2020 IEEE International Geoscience and Remote Sensing Symposium, Waikoloa, HI, USA, 26 September-2 October 2020; pp. 3525-3528. [CrossRef]

31. da Silva, J.C.B.; Santos-Ferreira, A.M.; Rieu, P.; Moreau, T.; Borde, F.; Boy, F.; Maraldi, C.; Picot, N.; Donlon, C. Detection of internal solitary waves with conventional and advanced SAR altimetry processing methods: Preliminary results. In Proceedings of the 2020 IEEE International Geoscience and Remote Sensing Symposium, Waikoloa, HI, USA, 26 September-2 October 2020; pp. 3521-3524. [CrossRef]

32. Zhang, Y.H.; Xu, K.; Li, M.T.; Li, J.; Liu, H.G.; Wang, X.Z. Study on spaceborne topography mapping altimeter. Remote Sens Technol. Appl. 1999, 14,11-14. [CrossRef]

33. Yang, J.S.; Ren, L.; Zheng, G. The first quantitative remote sensing of the ocean by Interferometric Imaging Radar Altimeter onboard the Tiangong-2. Haiyang Xuebao 2017, 39, 129-130. [CrossRef]

34. Kong, W.Y.; Chong, J.S.; Tan, H. Performance analysis of ocean surface topography altimetry by Ku-Band near-nadir interferometric SAR. Remote Sens. 2017, 9, 933-947. [CrossRef]

35. Bao, Q.L.; Yin, X.B.; Zou, J.H.; Lin, M.I.; Zhang, Y.G.; Zhang, Y.H. The wind speed inversion and in-orbit assessment of imaging altimeter on Tiangong-2 space station. In Proceedings of the 2018 IEEE International Geoscience and Remote Sensing Symposium, Valencia, Spain, 22-27 July 2018; pp. 1005-1008. [CrossRef]

36. Ren, L.; Yang, J.S.; Jia, Y.J.; Dong, X.; Wang, J.; Zheng, G. Sea surface wind speed retrieval and validation of the interferometric imaging radar altimeter aboard the Chinese Tiangong-2 space laboratory. IEEE J. Sel. Top. Appl. Earth Observ. Remote Sens. 2018, 11, 4718-4724. [CrossRef] 
37. Liu, K.; Zhou, Z.Z.; Wan, X.; Hei, B.Q.; Xiong, S.P.; Wu, C.Y. Deep learning network integrated multi-spectral data and interferometric imaging radar altimeter data of Tiangong-2 for land use classification. In Proceedings of the Tiangong-2 Remote Sensing Application Conference; Springer: Singapore, 2019; pp. 232-240. [CrossRef]

38. Shi, X.J.; Dong, X.; Yang, J.F.; Zhang, Y.H. Study on water information extraction method based on Tiangong-2 interferometric imaging radar altimeter data. In Proceedings of the 2019 Photonics Electromagnetics Research Symposium, Xiamen, China, 17-20 December 2019; pp. 1322-1326. [CrossRef]

39. Wang, Y.H.; Kong, W.Y.; Chong, J.S. Preliminary study of oceanic eddies detected by Tiangong-2 interferometric imaging radar altimeter. In Proceedings of the Tiangong-2 Remote Sensing Application Conference; Springer: Singapore, 2019; pp. 323-332. [CrossRef]

40. Ren, L.; Yang, J.S.; Dong, X.; Jia, Y.J.; Zhang, Y.H. Preliminary significant wave height retrieval from interferometric imaging radar altimeter aboard the Chinese Tiangong-2 space laboratory. Remote Sens. 2021, 13, 2413-2428. [CrossRef]

41. Bai, X.L.; Liu, Z.Y.; Li, X.F.; Hu, J.J. Generation sites of internal solitary waves in the southern Taiwan Strait revealed by MODIS true-colour image observations. Int. J. Remote Sens. 2014, 35, 4086-4098. [CrossRef]

42. Sun, L.N.; Zhang, J.; Meng, J.M. Analysis of spatio-temporal distribution of internal solitary waves in the South China Sea and Sulu Sea (2010-2015). Adv. Mar. Sci. 2019, 37, 398-408. [CrossRef]

43. Davis, K.A.; Arthur, R.S.; Reid, E.C.; Rogers, J.S.; Fringer, O.B.; DeCarlo, T.M.; Cohen, A.L. Fate of internal waves on a shallow shelf. J. Geophys. Res. Oceans 2020, 125, C015377. [CrossRef]

44. da Silva, J.C.B.; Cerqueira, A.L.F. A note on radar altimeter signatures of internal solitary waves in the ocean. In Remote Sensing of the Ocean, Sea Ice, Coastal Waters, and Large Water Regions 2016; SPIE Digital Library: Edinburgh, UK, 2016; pp. 99990201-99990215. [CrossRef]

45. de Macedo, C.R.; da Silva, J.C.B. Internal wave dark-band signatures in ALOS-PALSAR imagery revealed by the standard deviation of the co-polarized phase difference. Remote Sens. 2020, 12, 2372. [CrossRef]

46. Sui, X.H.; Zhang, R.N.; Wu, F.L.; Li, Y.; Wan, X.Y. Sea surface height measuring using InSAR altimeter. Geod. Geodyn. 2017, 8, 278-284. [CrossRef]

47. Li, H.Y.; Du, T.; He, Y.J. Effects of wind on the internal waves SAR images. In Proceedings of the 2005 Annual Academic Conference of Chinese Society for Oceanography, Yinchuan, China, 9-11 October 2005; pp. 16-20. 